BMJ

Open

Gastroenterology

\title{
Prevalence and screening for anaemia in mild to moderate Crohn's disease and ulcerative colitis in the United States, 2010-2014
}

\author{
Eboselume Akhuemonkhan, ${ }^{1}$ Alyssa Parian, ${ }^{1}$ Kay Miller, ${ }^{2}$ Stephen Hanauer, ${ }^{3}$ \\ Susan Hutfless, ${ }^{1,4}$
}

To cite: Akhuemonkhan $\mathrm{E}$, Parian A, Miller $\mathrm{K}$, et al. Prevalence and screening for anaemia in mild to moderate Crohn's disease and ulcerative colitis in the United States, 2010-2014. BMJ Open Gastro 2017;4: e000155. doi:10.1136/ bmjgast-2017-000155

Received 18 May 2017 Revised 1 June 2017 Accepted 8 June 2017
'Division of Gastroenterology \& Hepatology, Department of Medicine, Johns Hopkins University, Baltimore, USA ${ }^{2}$ Truven Health Analytics, an IBM Company

${ }^{3}$ Division of Gastroenterology \& Hepatology, Department of Medicine, Northwestern

University, Chicago, USA

${ }^{4}$ Department of Epidemiology, Johns Hopkins School of

Public Health, Baltimore, USA

Correspondence to

Dr Susan Hutfless; shutfle1@ jhmi.edu

\section{ABSTRACT}

Background and aims: Anaemia affects up to $74 \%$ patients with Crohn's disease (CD) and ulcerative colitis (UC) and is correlated with decreased quality of life. The European Crohn's and Colitis Organisation (ECCO) recommends at least annual screening for irondeficiency anaemia. We aimed to determine the prevalence of anaemia, frequency of anaemia screening and factors associated with anaemia in a retrospective study of mild to moderate inflammatory bowel disease (IBD) in the USA.

Methods: Adults with at least two outpatient encounters for IBD between 2010 through 2014 who contributed laboratory information were identified from MarketScan, a US commercial claims database. Hospitalised patients were considered severe and excluded from the study. WHO criteria defined anaemia. Iron-deficiency anaemia was evaluated using ferritin and $\mathrm{C}$ reactive protein.

Results: The eligible population included 17059 adults, $43.9 \%$ with CD. During the 2-year median follow-up period, $68.1 \%$ of patients with $C D$ and $65.3 \%$ of patients with UC were screened for anaemia. The prevalence of anaemia among those screened was $32.4 \%$ in $\mathrm{CD}$ and $27.6 \%$ in UC. Among 669 persons with sufficient information, $79.2 \%$ of those with $C D$ and $85.1 \%$ of those with UC had iron-deficiency anaemia. Factors associated with anaemia were similar for those with CD and UC and included $\geq 6$ IBD-related outpatient visits, female sex, age and smoking.

Conclusions: More than $30 \%$ of patients with IBD in the USA were not screened for anaemia during a 2-year period. Approximately $82 \%$ of anaemic patients were iron deficient, although the absence of ferritin results limited the findings. Incorporation of screening for anaemia and, in particular, iron deficiency, should be a component of international treatment guidelines.

\section{INTRODUCTION}

Inflammatory bowel diseases (IBD) are chronic immune-mediated inflammatory disorders that encompass Crohn's disease (CD) and ulcerative colitis (UC). CD is a

\section{Summary box}

What is already known about this subject?

- Most patients with inflammatory bowel disease (IBD) $(67 \%)$ were screened for anaemia at least once during the median 2-year follow-up period. However, very few patients were screened annually as recommended by the guidelines.

- Among patients with anaemia, the majority did not receive laboratory tests (ie, ferritin) to test for iron-deficiency anaemia. Screening for irondeficiency anaemia is guideline recommended.

- Anaemia is a frequent complication of IBD.

- No study has examined adherence to anaemia screening guidelines.

What are the new findings?

- This is the first study to examine adherence to IBD anaemia screening.

- Of patients with mild to moderate IBD, $66.6 \%$ were screened at least once during the median 2-year follow-up.

- Fewer than $20 \%$ were screened annually.

- Among those screened, $32.4 \%$ of those with $C D$ and $27.6 \%$ of those with UC were anaemic.

- The majority of the anaemic patients lacked information on ferritin for iron-deficiency assessment.

- Among those with sufficient information, $82 \%$ of the anaemic patients with IBD were iron deficient.

How might it impact on clinical practice in the foreseeable future?

- Providers should screen their patients with IBD for anaemia annually. If the patient is anaemic, further laboratory testing for iron-deficiency anaemia is needed.

transmural disease that can affect any portion of the gastrointestinal tract, although it most commonly occurs in the ileum and proximal colon. ${ }^{1} \mathrm{UC}$ is a mucosal disease affecting only the colon. ${ }^{1}$ Between 1 and 1.6 million Americans $^{2-5}$ have IBD with an overall 
prevalence of 504 per 100000 in the adult population (CD 241 per 100000 , UC 263 per 100000$).^{6}$

Anaemia is a frequent complication of IBD. ${ }^{7-20}$ Estimates of the prevalence of anaemia vary widely with a range of $9-73 \%$ in outpatients and $32-74 \%$ during IBD admissions. ${ }^{4}$ Patients with CD are more likely to be anaemic than those with UC. ${ }^{18}{ }^{20-23}$ There are several potential causes of anaemia in IBD including iron deficiency, anaemia of chronic disease, vitamin $B_{12}$ deficiency, folate deficiency and drug-induced anaemia. ${ }^{7} 816$ 18-21 Multiple types of anaemia may be present concurrently. Iron-deficiency anaemia can result from insufficient dietary iron intake due to altered diet, diminished uptake in the small bowel from frequent bowel movements or chronic blood loss due to inflammatory changes and mucosal ulcerations. ${ }^{4} 11 \quad 15-172425$ During IBD flares, there is an increase in cytokine production that upregulates hepcidin, a protein that blocks iron absorption and inhibits iron release from epithelial cells and intestinal macrophages, leading to altered erythropoiesis and iron-deficiency anaemia. ${ }^{10} \quad 26 \quad 27$ During severe inflammation of the small intestine or after ileal resection, vitamin $B_{12}$ and folate deficiency can occur. ${ }^{16} 2428$ Drug-induced anaemia occurs subsequent to medications that inhibit erythropoiesis such as thiopurines that suppress bone marrow production, methotrexate that prevents folate synthesis and sulfasalazine, which inhibits folate absorption and can induce haemolysis. $^{162224}$

The recommended diagnostic criteria for anaemia in the general population uses the WHO haemoglobin definition $(<13 \mathrm{~g} / \mathrm{dL}$ in men or $<12 \mathrm{~g} / \mathrm{dL}$ in nonpregnant women). ${ }^{29-31}$ In the presence of anaemia, iron deficiency is diagnosed by evaluation of mean cell volume (MCV), ferritin, transferrin saturation, serum iron and total iron-binding capacity. Ferritin is regarded as the best initial diagnostic test for iron deficiency. ${ }^{29} 30$

Anaemia screening recommendations for patients with IBD were first published in 2007. ${ }^{11}$ The European Crohn's and Colitis Organisation (ECCO) reviewed and modified these recommendations and published guidelines in 2015. ECCO recommends at least annual measurement of haematocrit/haemoglobin for anaemia and iron-deficiency anaemia in patients with $\mathrm{IBD}^{28}$ Guidelines for anaemia screening and treatment also exist within the British Society of Gastroenterology $(\mathrm{BSG})^{32}$ and Polish National Consultant for Gastroenterology Working Group Recommendations. ${ }^{12}$ No studies have examined adherence to screening guidelines. Furthermore, only 12 studies have examined the prevalence of anaemia or its treatments outside of Europe including a total of 2839 patients predominately in single-centre studies conducted in the USA. ${ }^{4} 162333$

We aimed to determine the prevalence of anaemia, the frequency of screening and factors associated with anaemia among adults with CD and UC in the USA who were under the age of 65 using Truven Health
MarketScan ${ }^{\mathrm{i}}$ Commercial database 2010-2014. We restricted our study to patients with mild to moderate IBD treated exclusively in outpatient settings.

\section{METHODS}

\section{Study design}

We conducted a retrospective study of adults with IBD using the MarketScan database from 2010 to 2014. This database contains information obtained from large employers and health plans across the USA. ${ }^{34}$ The database consists of encounters of insured employees and their dependents through employer-provided health insurance plans. ${ }^{34}$ This database does not include individuals who receive insurance through Medicare, resulting in a maximum patient age of 64 .

\section{Study population}

Adults (18-64) with at least two outpatient encounters for IBD based on International Classification of Diseases, Clinical Modification, Ninth Edition (ICD-9-CM) codes of 555 for CD or 556 for UC were eligible. We excluded IBD encounters occurring in longterm care facilities where care may not represent the general IBD population (see online supplementary appendix A). We excluded individuals whose age at first IBD encounter was $<18$ years. Patients with more encounters for $\mathrm{CD}$ than $\mathrm{UC}$ were classified as conclusive $\mathrm{CD}$ and similarly for UC. Individuals whose IBD type was inconclusive (presence of an equal number of encounters for both $\mathrm{CD}$ and UC) were excluded $(\mathrm{n}=5)$. Individuals who had clinical conditions associated with anaemia but independent of IBD were excluded (pregnancy (ICD-9-CM V22.X), chronic kidney disease (585. $\mathrm{X}$ ), malignant cancers (see online supplementary appendix B) and liver transplant (50.5X)) because we aimed to study a population where IBD was the most likely source of anaemia. We defined mild to moderate IBD by excluding patients at the time of a hospitalisation for IBD and those with feeding tubes (ICD-9-CM V55.1 V44.1; Current Procedural Terminology (CPT) codes, 43246, 44300, 49440, 49441, 49442, 49446, 43760, 49450, 49451, 49452, 44372, 44371).

\section{Laboratory eligibility}

Not all plans that contribute to the MarketScan database contribute laboratory information; therefore, patients were eligible if they had at least one laboratory result for any test. The laboratory eligibility date was extrapolated to the 1st of January of the year associated with the first available test result.

${ }^{\mathrm{i}}$ MarketScan is a registered trademark of Truven Health Analytics Inc, an IBM Company. 


\section{Study period}

Follow-up began when patients had their first IBD encounter or became laboratory eligible, whichever came last. This follow-up period ended on either the first IBD-related hospitalisation or on the last date of enrolment. Censoring was done at first inpatient encounter because we aimed to capture mild to moderate IBD cohort treated as outpatients. The majority of patients with IBD are now treated predominately as outpatients. ${ }^{35-37}$ Patients were required to have at least 1 year of continuous enrolment after the start of follow-up in order to assess annual screening.

\section{Screening for anaemia and iron-deficiency anaemia}

Screening for anaemia was defined by the presence of a laboratory result for anaemia testing. Laboratory tests and results were identified using their Logical Observation Identifiers Names and Codes (LOINC) (see online supplementary appendix $\mathrm{C}$ ). Anaemia was determined using WHO haemoglobin/haematocrit levels based on age and sex (see online supplementary appendix D) including haematocrit $<39 \%$ in men and $<36 \%$ in women or haemoglobin $<13.0 \mathrm{~g} / \mathrm{dL}$ in men and $<12.0 \mathrm{~g} / \mathrm{dL}$ in women. ${ }^{31}$ We excluded encounters with haematocrit/haemoglobin values that were reported as zero. Individuals with anaemia were examined for iron deficiency, which was assessed using $\mathrm{C}$ reactive protein (CRP) and ferritin measured \pm 30 days of the reduced haemoglobin or haematocrit. Iron-deficiency anaemia was considered in individuals who met one of two conditions: (1) ferritin $<30 \mathrm{ng} / \mathrm{mL}$ or (2) ferritin between 30 and $100 \mathrm{ng} / \mathrm{mL}$ combined with elevated CRP based on the laboratory-provided upper limit (see online supplementary appendix E).

\section{Adherence assessment}

We assessed adherence to having at least one screening for anaemia by calculating yearly intervals from the patients' first anaemia screening, therefore the start dates for year zero was the date of first screening test and the interval start dates that followed were in 1 year increments. Our analyses accounted for patients who returned earlier than 1 year for their next screening, by including in the subsequent year interval, tests that occurred within 60 days of the start date of that interval (see online supplementary appendix F).

\section{Factors that may be associated with anaemia}

We collected information on other characteristics to help us understand the IBD cohort and their disease severity. These factors were examined as potential predictors of anaemia. These included type of IBD, sex, older age (50-64 years) at first IBD encounter versus younger (18-34; 35-49 years), number of outpatient visits and smoking (ICD-9-CM 305.1X). We examined the use of IBD medications during the study period to understand the disease severity of the cohort but did not include these as potential predictors of anaemia due to concerns of confounding by indication (see online supplementary appendix G).

\section{Statistical analysis}

Analyses were performed separately for CD and UC. We calculated frequency distributions, median and range for demographic variables including age at first IBD encounter, sex, median duration of follow-up, number of healthcare encounters, smoking status and IBD-related medication use. The average number of outpatient visits for each patient was calculated by dividing the total number of outpatient visits by the number of years of study follow-up.

We evaluated the prevalence of screening for anaemia based on the number of individuals who had a test result for haemoglobin or haematocrit over the total eligible population. To evaluate the prevalence of anaemia, we calculated the number of individuals who met WHO criteria for anaemia at any point during the study period over the total number of individuals with haemoglobin/haematocrit results.

We calculated the annual frequency of testing for anaemia to assess adherence to the annual screening recommendation by examining the proportion of patients with IBD with at least one haemoglobin/haematocrit result during each consecutive year of eligibility divided by the total number of people with follow-up of at least 2 years $(\mathrm{N}=13751)$.

We calculated the prevalence of iron-deficiency anaemia by dividing the number of individuals who met the iron-deficiency definition by the number of individuals with sufficient information to asses iron deficiency based on laboratory results.

We performed multivariable logistic regressions to evaluate factors associated with anaemia based on factors available in our cohort as well as factors associated with anaemia from previous studies. ${ }^{23} 33$ All analyses were performed using SAS V.9.4 (SAS Institute, Cary, North Carolina, USA). The Johns Hopkins Institutional Review Board (IRB) approved this study.

\section{RESULTS}

Demographics

Of 380386 patients with at least two IBD encounters during 2010-2014, 44862 had laboratory information available and 17059 (7493 CD and $9566 \mathrm{UC}$ ) met our inclusion criteria (figure 1). The median ages were 44 years for $\mathrm{CD}$ and 46 years for UC. Fifty-nine and $56 \%$ of patients with $\mathrm{CD}$ and UC, respectively, were female, and the median follow-up was 2.0 years for both $\mathrm{CD}$ and UC. Sixty-one per cent of those with CD and $48.4 \%$ of those with UC had six or more IBD-related outpatient visits. Steroids were the most common medication used by patients with $\mathrm{CD}(45.8 \%)$ and aminosalicylates were the most common medication in UC $(56.8 \%)$ (table 1$)$. 
Figure 1 Inclusion criteria in mild to moderate Crohn's disease and ulcerative colitis in MarketScan, 2010-2014.
MarketScan Cohort with at least 2 inpatient or outpatient IBD encounters, 2010-2014

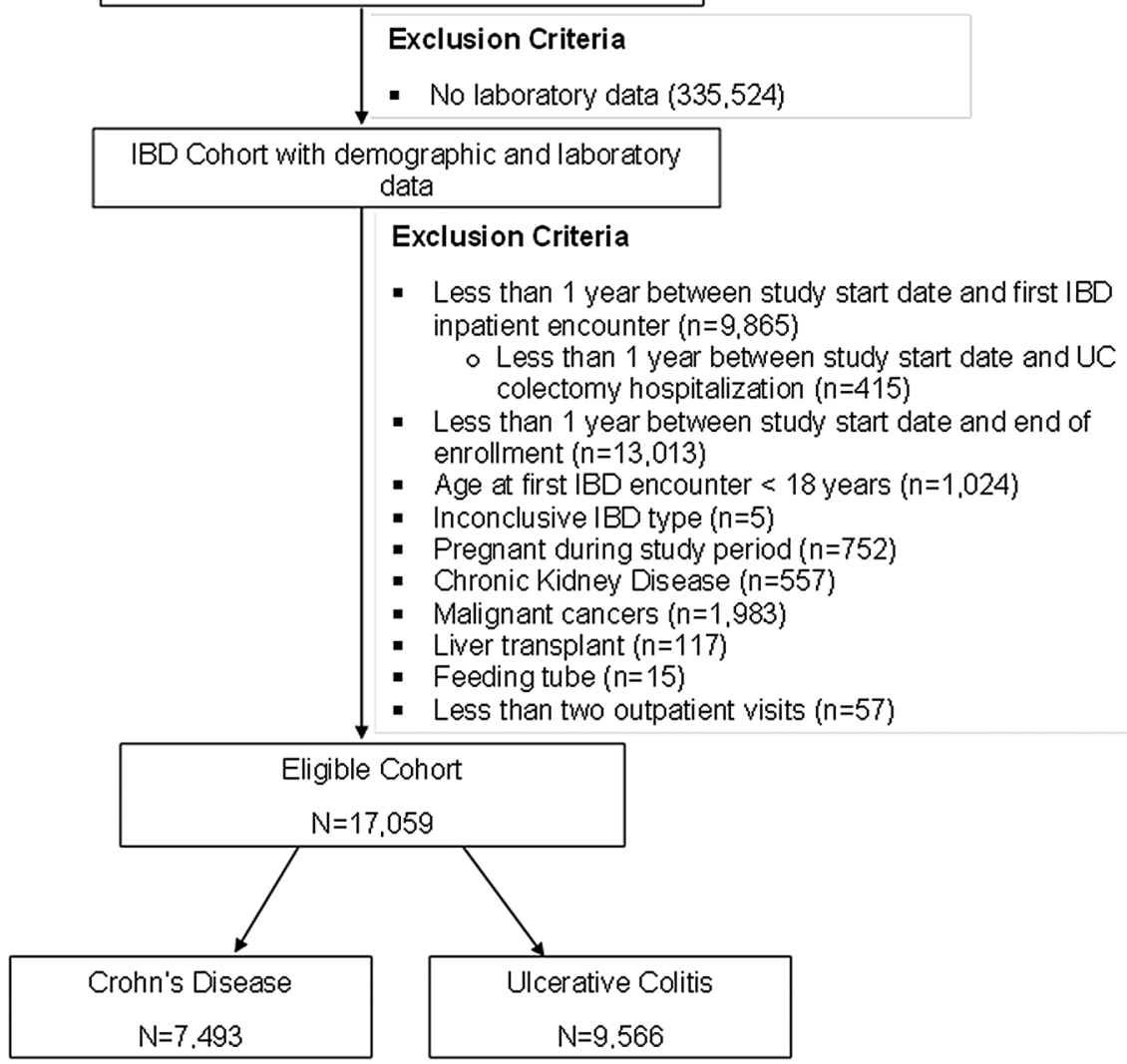

Table 1 Demographic characteristics of mild to moderate Crohn's disease and ulcerative colitis in MarketScan, 2010-2014

\begin{tabular}{lll}
\hline & Crohn's disease & Ulcerative colitis \\
N=9566
\end{tabular}


CD

$n=7,493$

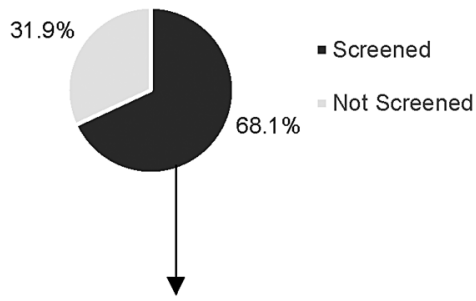

CD

$n=5,104$

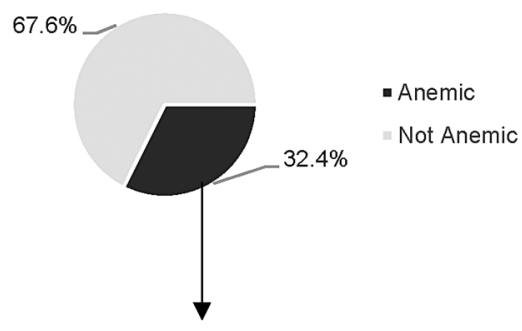

CD

$n=1,652$
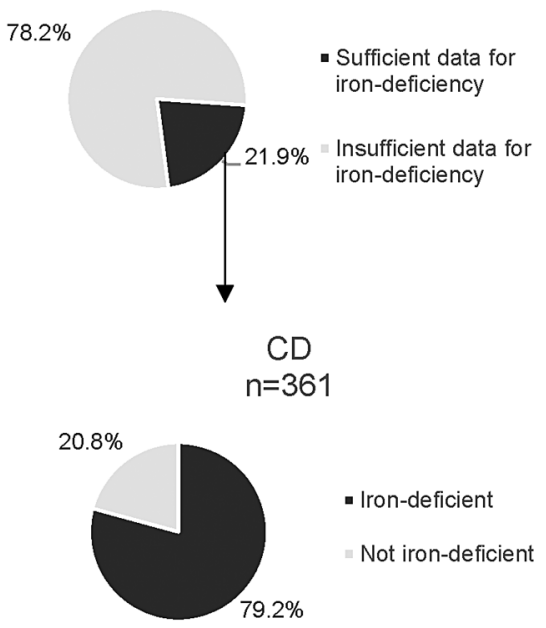

UC

$n=9,566$

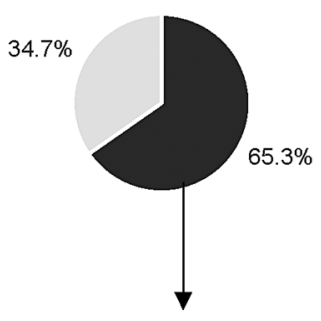

- Screened

Not Screened

UC

$n=6,249$

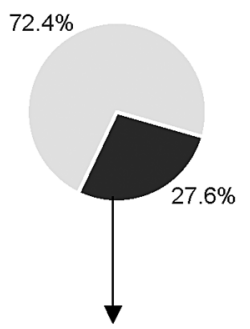

- Anemic

Not Anemic

UC

$\mathrm{n}=1,727$

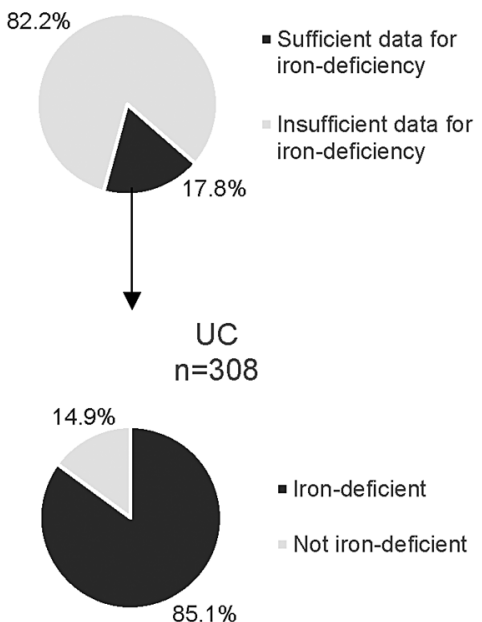

Figure 2 Screening and prevalence of anaemia and iron deficiency in mild to moderate Crohn's disease and ulcerative colitis in MarketScan, 2010-2014.

\section{Anaemia screening and prevalence}

At least two-thirds of patients with $\mathrm{CD}(68.1 \%)$ and $\mathrm{UC}$ $(65.3 \%)$ were screened for anaemia (figure 2$)$. Among screened patients, anaemia was present in $32.4 \%$ of patients with $\mathrm{CD}$ and $27.6 \%$ of patients with UC (figure 2). Of this cohort, $18.1 \%$ were screened at least once per year during the years that they contributed information.

\section{Prevalence of iron-deficiency anaemia}

Among patients who met WHO criteria for anaemia, $19.8 \%(\mathrm{n}=669)$ had an associated ferritin measurement and CRP measurement (for those with ferritin 30$100 \mathrm{ng} / \mathrm{mL}$ ) and could be assessed for iron-deficiency anaemia (figure 2). Of these, iron-deficiency anaemia was present in $79.2 \%$ of 361 patients with $\mathrm{CD}$ and $85.1 \%$ of 308 patients with UC. Iron deficiency could not be assessed in $80.2 \%(\mathrm{n}=2710)$ of anaemic patients, either because they did not have any ferritin or CRP results within 30 days of the anaemia result.

\section{Factors associated with anaemia}

Factors associated with anaemia did not differ between CD and UC. Risk factors for anaemia in both $\mathrm{CD}$ and UC included greater numbers of IBD-related outpatient visits, female sex and younger age (table 2). CD smokers were less likely to be anaemic (OR $0.7 ; 95 \%$ CI 0.6 to 0.9 ). 
Table 2 Adjusted + ORs for factors associated with anaemia among the screened mild to moderate inflammatory bowel disease (IBD) in MarketScan, 2010-2014

\begin{tabular}{|c|c|c|c|}
\hline & $\begin{array}{l}\text { Inflammatory bowel disease } \\
\text { OR }(95 \% \mathrm{Cl}) \\
\mathrm{N}=11353\end{array}$ & $\begin{array}{l}\text { Crohn's disease } \\
\text { OR }(95 \% \mathrm{Cl}) \\
\mathrm{N}=5104\end{array}$ & $\begin{array}{l}\text { Ulcerative colitis } \\
\text { OR }(95 \% \mathrm{Cl}) \\
\mathrm{N}=6249\end{array}$ \\
\hline Crohn's disease vs ulcerative colitis & $1.1(1.0 \text { to } 1.2)^{*}$ & & \\
\hline Female vs male & $1.5(1.4 \text { to } 1.7)^{\star \star \star}$ & $1.5(1.3 \text { to } 1.7)^{\star \star \star}$ & $1.5(1.4 \text { to } 1.7)^{\star \star \star}$ \\
\hline \multicolumn{4}{|c|}{ Total number of IBD outpatient visits during follow-up } \\
\hline $2-5$ visits & Reference & Reference & Reference \\
\hline $6-10$ visits & $1.4(1.3 \text { to } 1.5)^{\star \star \star}$ & $1.3(1.1 \text { to } 1.6)^{\star \star}$ & $1.5(1.3 \text { to } 1.7)^{\star \star \star}$ \\
\hline$>10$ visits & $2.4(2.2 \text { to } 2.7)^{\star \star *}$ & $2.1(1.8 \text { to } 2.4)^{\star * *}$ & $2.8(2.4 \text { to } 3.2)^{* * *}$ \\
\hline Smoker vs non-smoker/unknown & $0.7(0.6 \text { to } 0.9)^{* *}$ & $0.7(0.6 \text { to } 0.9)^{\star *}$ & $0.8(0.6$ to 1.0$)$ \\
\hline \multicolumn{4}{|l|}{ Age at first IBD encounter } \\
\hline $50-64$ years & Reference & Reference & Reference \\
\hline 18-34 years & $1.1(1.0 \text { to } 1.3)^{*}$ & 1.1 (0.9 to 1.2$)$ & $1.2(1.0 \text { to } 1.4)^{*}$ \\
\hline $35-49$ years & $1.0(0.9$ to 1.1$)$ & 1.0 (0.9 to 1.2$)$ & 1.1 (0.9 to 1.2$)$ \\
\hline
\end{tabular}

\section{DISCUSSION}

Approximately two-thirds of patients were screened for anaemia during the median 2 year follow-up period (68.1\% CD, $65.3 \%$ UC). However, only $18.1 \%$ of the cohort underwent annual screening as recommended by ECCO and other guidelines. Of the $29.8 \%$ of patients with IBD with anaemia, iron deficiency was common (81.9\%) among those with sufficient information to make the calculation.

No other study has examined the adherence to screening guidelines, so it is unknown if the results in this insured American population are generalisable to other settings. At least one-third of the screened cohort had anaemia, which is similar to published European studies on anaemia (24-33\%) in IBD. ${ }^{4} 2023$ Our findings were also similar to predictors of anaemia in the USA. A recently published study on anaemia in a US IBD cohort showed a statistically significant higher prevalence of anaemia in $\mathrm{CD}$ compared with $\mathrm{UC}$ ( $\mathrm{p}$ value 0.001$){ }^{33}$ This mirrors our findings and also findings from other European studies. ${ }^{13} \quad 20 \quad 21$ However, these studies included anaemia assessed during inpatient stays when patients may be most likely to have anaemia. To the best of our knowledge, this is the first study of anaemia in the USA. Patients with IBD are treated exclusively as outpatients where the majority of care occurs for contemporary patients. In the US PharMetrics database, there were 20 IBD outpatient encounters for every one hospitalisation. ${ }^{37}$ In a Dutch study of patients with IBD recruited from an outpatient clinic between September 2014 and February 2015, only 10.9\% had a hospital admission during the year prior to their outpatient visit. $^{35}$

Anaemia is associated with increased disease activity, healthcare usage, mortality and low quality of life. ${ }^{78121315171820242628}$ Disease activity is reflected by more frequent outpatient visits and hospitalisations. Frequent outpatient visits was the strongest predictor of anaemia (OR 2.4) demonstrating that these patients are using healthcare services more than their peers and is consistent with increased usage of anaemia associated with other chronic diseases. The increase in usage could be due to greater disease activity or perhaps to the anaemia itself. The effects of anaemia on general wellbeing cannot be overstated. In a study where quality of life was assessed using the validated Short Inflammatory Bowel Disease Questionnaire (SIBDQ), patients with anaemia had lower scores compared with non-anaemic patients with IBD after adjusting for disease activity. ${ }^{23}$ In this study, the failure to identify the cause of anaemia (ie, lack of ferritin and CRP results after documented anaemia) and failure to perform annual assessments for anaemia in general provide evidence for a gap between guidelines and clinical practice. Adherence to the anaemia screening guidelines has the potential to impact the clinical and social lives of patients with IBD.

There are several mechanisms for iron-deficiency anaemia in IBD including iron loss from bleeding mucosal ulcerations, decreased iron intake and impaired absorption. In particular, patients with $\mathrm{CD}$ with inflammation of the duodenum and upper jejunum develop impaired iron absorption leading to anaemia. ${ }^{38}$ This may explain the higher prevalence in $\mathrm{CD}$ compared with UC. ${ }^{16}{ }^{21}$ The higher prevalence of anaemia in women may be explained by menstruation.

Anaemia presents significant economic burden to patients and their caregivers. A recent estimate of the average annual healthcare cost incurred per anaemic patient with IBD was $\$ 19113$ compared with $\$ 7678$ in non-anaemic patients with IBD $(p<0.001) .{ }^{39}$ Iron replacement therapy is the mainstay of treating anaemia and improves quality of life. ${ }^{14} 26{ }^{40}$ Concomitant to effective therapy for $\mathrm{CD}$ and $\mathrm{UC}$, early diagnosis and treatment of anaemia could potentially decrease hospitalisations, lower healthcare costs and, most importantly, improve quality of life. 
Our study has several strengths. The MarketScan database used in our study is representative of the privately insured US population which comprises $55 \%$ of the US population. $^{34}$ Our study cohort captures care provided in the outpatient setting where preventive care is recommended for patients with IBD. ${ }^{41}$ We created our inclusion criteria to capture annual screening in a population with minimal comorbidities other than IBD, so as to obtain accurate estimates for the general IBD population. We allowed grace periods for laboratory assessments to maximise the number of individuals who met the criteria and to allow leniency in order to better mimic the clinical experience where an 'annual' visit may occur a few months early or late in any given year.

Limitations of our study include the potential overestimation of iron-deficiency anaemia and limited generalisability to the youngest and oldest patients with IBD. Our estimate of iron-deficiency anaemia is very likely an overestimate as so few individuals had ferritin results available within 30 days of their anaemia laboratory result. If assessment of iron deficiency is a potential indicator of quality care, major changes in practice patterns will be needed in laboratory ordering to meet this assessment goal. We could not assess prevalence of anaemia in paediatric or older IBD population because our database included persons 64 years and under and we included only patients over the age of 18 because the current screening recommendations are for adults.

In conclusion, one-third of screened US IBD patients have anaemia. One in three patients with IBD in the USA were never screened for anaemia and $81.9 \%$ were not screened annually. Approximately $82 \%$ of evaluated anaemic patients were iron deficient although the small proportion of patients with ferritin results limited the findings. Adherence to the available guidelines from Europe and incorporation of anaemia screening protocols into US practice and quality guidelines should be considered.

Contributors EA contributed to study concept and study design, data acquisition, analysis and data interpretation, drafting of manuscript and critical revision of manuscript for important intellectual content. AP was involved in drafting of manuscript and critical revision of manuscript for important intellectual content. KM and SH1 critically revised manuscript for important intellectual content. SH2 contributed to study concept and study design, data acquisition, analysis and data interpretation, drafting of manuscript, critical revision of manuscript for important intellectual content and study supervision. All the authors of this manuscript have approved the final version submitted.

Funding This study was funded in full by an investigator-initiated grant from Luitpold Pharmaceuticals.

Competing interests KM is an employee of Truven Health Analytics, an IBM Company. SH has served as a consultant for AbbVie, Actavis, Amgen, Celgene, Celltrion, Hospira, Janssen, Merck, Nestle, Novartis, Pfizer, Prometheus, Receptos, Salix, Seres Health, Shire, Takeda, Tigenex, UCB Pharma and Speaker for AbbVie, Janssen and Takeda. SH received research funding from Luitpold Pharmaceuticals.

Ethics approval Johns Hopkins Medicine.

Provenance and peer review Not commissioned; externally peer reviewed.

Data sharing statement The database used in this study can be obtained with a licence from Truven Health, an IBM company.

\section{REFERENCES}

1. Abraham $\mathrm{C}$, Cho JH. Inflammatory bowel disease. $\mathrm{N}$ Engl J Med 2009;361:2066-78.

2. Shivashankar R, Tremaine W, Harmsen S, et al. Updated incidence and prevalence of Crohn's disease and ulcerative colitis in Olmsted County, Minnesota (1970-2010). Am J Gastroenterol 2014;109(Suppl 2):S499.

3. Loftus EV Jr. Clinical epidemiology of inflammatory bowel disease: incidence, prevalence, and environmental influences. Gastroenterology 2004;126:1504-17.

4. Wilson A, Reyes E, Ofman J. Prevalence and outcomes of anemia in inflammatory bowel disease: a systematic review of the literature. Am J Med 2004;116(Suppl 7A):44S-9S.

5. Kappelman MD, Rifas-Shiman S, Kleinman K, et al. The prevalence and geographic distribution of Crohn's disease and ulcerative colitis in the United States. Clin Gastroenterol Hepatol 2007;5:1424-9.

6. Kappelman MD, Moore KR, Allen JK, et al. Recent trends in the prevalence of Crohn's disease and ulcerative colitis in a commercially insured US population. Dig Dis Sci 2013;58:519-25.

7. Rogler G, Vavricka S. Anemia in inflammatory bowel disease: an under-estimated problem? Front Med (Lausanne) 2014;1:58-58.

8. Nielsen $\mathrm{OH}$, Ainsworth $\mathrm{M}$, Coskun $\mathrm{M}$, et al. Management of iron-deficiency anemia in inflammatory bowel disease: a systematic review. Medicine (Baltimore) 2015;94:e963.

9. Blumenstein I, Dignass A, Vollmer S, et al. Current practice in the diagnosis and management of IBD-associated anaemia and iron deficiency in Germany: the German AnaemIBD Study. J Crohns Colitis 2014;8:1308-14.

10. Stein J, Hartmann F, Dignass AU. Diagnosis and management of iron deficiency anemia in patients with IBD. Nat Rev Gastroenterol Hepatol 2010;7:599-610.

11. Gasche C, Berstad A, Befrits R, et al. Guidelines on the diagnosis and management of iron deficiency and anemia in inflammatory bowel diseases. Inflamm Bowel Dis 2007;13:1545-53.

12. Kaniewska M, Bartnik W, Gonciarz M, et al. Iron deficiency anaemia in patients with inflammatory bowel disease: national consultant for gastroenterology working group recommendations. Prz Gastroenterol 2014:9:259-63.

13. Bager $\mathrm{P}$, Befrits $\mathrm{R}$, Wikman $\mathrm{O}$, et al. High burden of iron deficiency and different types of anemia in inflammatory bowel disease outpatients in Scandinavia: a longitudinal 2-year follow-up study. Scand J Gastroenterol 2013;48:1286-93.

14. Lee TW, Kolber MR, Fedorak RN, et al. Iron replacement therapy in inflammatory bowel disease patients with iron deficiency anemia: a systematic review and meta-analysis. J Crohns Colitis 2012;6:26775.

15. Ott C, Liebold A, Takses A, et al. High prevalence but insufficient treatment of iron-deficiency anemia in patients with inflammatory bowel disease: results of a population-based cohort. Gastroenterol Res Pract 2012;2012:595970.

16. Kulnigg S, Gasche C. Systematic review: managing anaemia in Crohn's disease. Aliment Pharmacol Ther 2006;24:1507-23.

17. Danese S, Hoffman C, Vel S, et al. Anaemia from a patient perspective in inflammatory bowel disease: results from the European federation of Crohn's and ulcerative colitis association's online survey. Eur J Gastroenterol Hepatol 2014;26:1385-91.

18. Antunes CV, Hallack Neto AE, Nascimento CR, et al. Anemia in inflammatory bowel disease outpatients: prevalence, risk factors, and etiology. Biomed Res Int 2015;2015:728925.

19. Alves RA, Miszputen SJ, Figueiredo MS. Anemia in inflammatory bowel disease: prevalence, differential diagnosis and association with clinical and laboratory variables. Sao Paulo Med $J$ 2014;132:140-6.

20. Lupu A, Diculescu M, Diaconescu R, et al. Prevalence of anemia and iron deficiency in Romanian patients with inflammatory bowel disease: a prospective multicenter study. J Gastrointestin Liver Dis 2015;24:15-20.

21. Filmann N, Rey J, Schneeweiss S, et al. Prevalence of anemia in inflammatory bowel diseases in European countries: a systematic review and individual patient data meta-analysis. Inflamm Bowel Dis 2014;20:936-45.

22. Bager $\mathrm{P}$, Befrits $\mathrm{R}$, Wikman $\mathrm{O}$, et al. The prevalence of anemia and iron deficiency in IBD outpatients in Scandinavia. Scand $J$ Gastroenterol 2011;46:304-9.

23. Koutroubakis IE, Ramos-Rivers C, Regueiro M, et al. Persistent or recurrent anemia is associated with severe and disabling inflammatory bowel disease. Clin Gastroenterol Hepatol 2015;13:1760-6.

24. Gisbert JP, Gomollón F. Common misconceptions in the diagnosis and management of anemia in inflammatory bowel disease. $\mathrm{Am}$ J Gastroenterol 2008;103:1299-307. 
25. Stein J, Bager P, Befrits R, et al. Anaemia management in patients with inflammatory bowel disease: routine practice across nine European countries. Eur J Gastroenterol Hepatol 2013;25: 1456-63.

26. Evstatiev R, Marteau P, Iqbal T, et al. FERGlcor, a randomized controlled trial on ferric carboxymaltose for iron deficiency anemia in inflammatory bowel disease. Gastroenterology. 2011;141:846-53. e1-2.

27. Jimenez K, Kulnigg-Dabsch S, Gasche C. Management of iron deficiency anemia. Gastroenterol Hepatol (NY) 2015;11:241-50.

28. Dignass AU, Gasche C, Bettenworth D, et al. European consensus on the diagnosis and management of iron deficiency and anaemia in inflammatory bowel diseases. J Crohns Colitis 2015;9:211-22.

29. Goddard AF, James MW, McIntyre AS, et al, British Society of Gastroenterology. Guidelines for the management of iron deficiency anaemia. Gut 2011;60:1309-16.

30. Killip S, Bennett JM, Chambers MD. Iron deficiency anemia. Am Fam Physician 2007;75:671-8.

31. WHO, UNICEF U. Iron Deficiency Anemia: Assessment, Prevention and Control. A Guide for Programme Managers. WHO/NHD/01.3. http://www.who.int/nutrition/publications/micronutrients/anaemia iron_deficiency/WHO_NHD_01.3/en/ (accessed 15 Jul 2015).

32. Mowat C, Cole A, Windsor $\bar{A}$, et al. Guidelines for the management of inflammatory bowel disease in adults. Gut 2011;60:571-607.

33. Koutroubakis IE, Ramos-Rivers C, Regueiro M, et al. Five-year period prevalence and characteristics of anemia in a large US inflammatory bowel disease cohort. J Clin Gastroenterol 2016;50:638-43.
34. Hansen LG. Health Research Data for the Real World: The MarketScan Databases. http://images.info.truvenhealth.biz/Web/ TruvenHealthAnalytics/\%

7B87d8921a-c27c-4382-bd88-d8ec9011de70\%7D_2016_Truven Health_MarketScan_white_paper_for_Life_Sciences.pdf (accessed 3 Aug 2016).

35. Severs M, Petersen RE, Siersema PD, et al. Self-reported health care utilization of patients with inflammatory bowel disease correlates perfectly with medical records. Inflamm Bowel Dis 2016;22:688-93.

36. Niewiadomski O, Studd C, Hair C, et al. Prospective population-based cohort of inflammatory bowel disease in the biologics era: disease course and predictors of severity J Gastroenterol Hepatol 2015;30:1346-53.

37. Kappelman MD, Porter CQ, Galanko JA, et al. Utilization of healthcare resources by U.S. children and adults with inflammatory bowel disease. Inflamm Bowel Dis 2011;17:62-8.

38. Gasche C, Lomer MC, Cavill I, et al. Iron, anaemia, and inflammatory bowel diseases. Gut 2004;53:1190-7.

39. Nissenson AR, Wade S, Goodnough T, et al. Economic burden of anemia in an insured population. J Manag Care Pharm 2005;11:565-74.

40. Gisbert JP, Bermejo F, Pajares R, et al. Oral and intravenous iron treatment in inflammatory bowel disease: hematological response and quality of life improvement. Inflamm Bowel Dis 2009;15:1485-91.

41. Farraye FA, Melmed GY, Lichtenstein GR, et al. ACG clinical guideline: preventive care in inflammatory bowel disease. $A m$ J Gastroenterol 2017;112:241-58. 